\title{
Fixed Points of Non Self Maps
}

\author{
V.Naga Raju \\ Department of Mathematics \\ College of Engineering \\ Osmania University \\ Hyderabad-500007, India
}

\begin{abstract}
The purpose of this paper is to present some fixed point theorems for non self maps in $\mathrm{d}_{\mathrm{p}}$-complete topological spaces which extend the results of Linda Marie Saliga.
\end{abstract}

\section{Keywords}

$\mathrm{d}_{\mathrm{p}^{-}}$complete topological spaces, $d$-complete topological spaces and non self maps.

\section{INTRODUCTION}

Troy L. Hicks [5] has introduced $d$-complete topological spaces, attributing the basic ideas of these spaces to Kasahara ([8], [9]) and Iseki [7] as follows:

1.1 Definition: A topological space $(X, t)$ is said to be $d$ complete if there is a mapping $d: X \times X \rightarrow[0, \infty)$ such that (i) $d(x, y)=0 \Leftrightarrow x=y$ and (ii) $\left\langle x_{n}>\right.$ is a sequence in $X$ such that $\sum_{n=1}^{\infty} d\left(x_{n}, x_{n+1}\right)$ is convergent implies that $<x_{n}>$ converges in $(X, t)$.

In this paper we introduce $\mathrm{d}_{\mathrm{p}}$ - complete topological spaces as a generalization of $d$-complete topological spaces for any integer $p \geq 2$. For a non-empty set $X$, let $X^{p}$ be its $p$-fold cartesian product.

1.2 Definition: A topological space $(X, t)$ is said to be $d_{p}$ complete if there is a mapping $d_{p}: X^{p} \rightarrow[0, \infty)$ such that (i) $d_{p}\left(x_{1}, x_{2}, \ldots, x_{p}\right)=0 \Leftrightarrow x_{1}=x_{2}=\ldots=x_{p}$ and (ii) $\left\langle x_{n}\right\rangle$ is a sequence in $X$ with $\lim _{n \rightarrow \infty} d_{p}\left(x_{n}, x_{n+1}, x_{n+2}, \ldots, x_{n+p-1}\right)=0 \quad$ implies that $<x_{n}>$ converges to some point in $(X, t)$. A $d_{p}$ - complete topological space is denoted by $\left(X, t, d_{p}\right)$

1.3 Remark: The function $d$ in the Definition 1.1 and the function $d_{2}$ (the case $p=2$ ) in Definition 1.2 are both defined on $X \times X$ and satisfy condition (i) of the definitions which are identical. Since the convergence of an infinite series $\sum_{n=1}^{\infty} \alpha_{n}$ of real numbers implies that $\lim _{n \rightarrow \infty} \alpha_{n}=0$, but not conversely; it follows that every $d$-complete topological space is $d_{2}$ - complete, but not conversely. Therefore the class of $d_{2}$ - complete topological spaces is wider than the class of $d$ complete spaces and hence a separate study of fixed point theorems of self-maps on $d_{2}$ - complete topological spaces is meaningful.

The purpose of this paper is to establish certain fixed point theorems of non self-maps of $d_{p}$ - complete topological spaces for $p \geq 2$.

\section{PRELIMINARIES}

Let $X$ be a non-empty set. A mapping $d_{p}: X^{p} \rightarrow[0, \infty)$ is called a p-non-negative on $X \quad$ provided $d_{p}\left(x_{1}, x_{2}, \ldots, x_{p}\right)=0 \Leftrightarrow x_{1}=x_{2}=\ldots=x_{p}$.

2.1 Definition: Suppose $(X, t)$ is a topological space and $d_{p}$ is a $p$-non negative on $X$. A sequence $\left\langle x_{n}>\right.$ in $X$ is said to be a $d_{p^{-}}$Cauchy sequence if $d_{p}\left(x_{n}, x_{n+1}, \ldots, x_{n+p-1}\right) \rightarrow 0$ as $n \rightarrow \infty$.

In view of Definition 2.1, a topological space $(X, t)$ is $d_{p}$ complete if there is a $p$-non- negative $d_{p}$ on $X$ such that every $d_{p}$ - Cauchy sequence in $X$ converges to some point in $(X, t)$.

If $T$ is a self map of a non-empty set $X$ and $X \in X$, then the orbit of $x, O_{T}(x)$ is given by $O_{T}(x)=\left\{x, T x, T^{2} x, \ldots\right\}$. If $T$ is a self map of a topological space $X$, then a mapping $G: X \rightarrow[0, \infty)$ is said to be T-orbitally lower semicontinuous (resp. T-orbitally continuous) at $x^{*} \in X$ if $\left\langle x_{n}\right\rangle$ is a sequence in $O_{T}(x)$ for some $x \in X$ with $x_{n} \rightarrow x^{*}$ as $n \rightarrow \infty$ then $G\left(x^{*}\right) \leq \liminf _{n \rightarrow \infty} G\left(x_{n}\right)$ ( resp. $\left.G\left(x^{*}\right)=\lim _{n \rightarrow \infty} G\left(x_{n}\right)\right)$. A self map $T$ of topological space $X$ is said to be w-continuous at $x \in X$ if $x_{n} \rightarrow x$ as $n \rightarrow \infty$ implies $T x_{n} \rightarrow T x$ as $n \rightarrow \infty$.

If $d_{p}$ is a $p$-non-negative on a non-empty set $X$, and $T: X \rightarrow X$ then we write, for simplicity of notation, that

(2.2) $G_{p}(x):=d_{p}\left(x, T x, T^{2} x, \ldots, T^{p-1} x\right)$ for $x \in X$

Clearly we have

(2.3) $G_{p}(x)=0$ if and only if $x$ is a fixed point of $T$.

\section{MAIN RESULTS}

3.1 Theorem: Suppose $\left(X, t, d_{p}\right)$ is a $d_{p}$ completeHausdorff topological space, $\mathrm{C}$ is a closed subset of $\mathrm{X}$ and $\mathrm{T}: \mathrm{C} \rightarrow \mathrm{X}$ is an open mapping with $\mathrm{C} \subset \mathrm{T}(\mathrm{C})$. Suppose $\mathrm{d}_{\mathrm{p}}\left(\mathrm{x}_{1}, \quad \mathrm{x}_{2}, \ldots, \quad \mathrm{x}_{\mathrm{p}}\right) \leq \mathrm{k}\left(\mathrm{d}_{\mathrm{p}}\left(\mathrm{Tx}_{1}, \mathrm{Tx}_{2}, \ldots, \mathrm{Tx}_{\mathrm{p}}\right)\right)$ for all 
$\mathrm{x}_{1}, \mathrm{x}_{2}, \ldots, \mathrm{x}_{\mathrm{p}} \in \mathrm{C}$, where $\mathrm{k}:[0, \infty) \rightarrow[0, \infty)$ is a non-decreasing function with $\mathrm{k}(0)=0$. Then $\mathrm{T}$ has a fixed point iff there exists an $\mathrm{x}_{0} \in \mathrm{C}$ with $\mathrm{k}^{\mathrm{n}}\left(\mathrm{d}_{\mathrm{p}}\left(\mathrm{T}^{\mathrm{p}-1} \mathrm{x}_{0}, \mathrm{~T}^{\mathrm{p}-2} \mathrm{x}_{0}, \ldots ., \mathrm{Tx}_{0}, \mathrm{x}_{0}\right)\right) \rightarrow 0$ as $\mathrm{n}$ $\rightarrow \infty$

Proof : If $\mathrm{x}, \mathrm{y} \in \mathrm{C}$ are such that $\mathrm{Tx}=\mathrm{Ty}$, then the inequality of the theorem gives $d_{p}(x, y, y, \ldots, y) \leq k\left(d_{p}(T x, T y, T y, \ldots ., T y)\right)$ $=\mathrm{k}(0)=0$ which gives $\mathrm{x}=\mathrm{y}$. Hence $\mathrm{T}$ is one-one. Thus $\mathrm{T}$ : $\mathrm{C} \rightarrow \mathrm{T}(\mathrm{C})$ is a bijective map and hence $\mathrm{T}^{-1}: \mathrm{T}(\mathrm{C}) \rightarrow \mathrm{C}$ exists. Since $\mathrm{T}$ is open (by hypothesis), it follows that $\mathrm{T}^{-1}$ is a continuous function and hence $\mathrm{T}^{-1}$ is a w-continuous function. Now first suppose that $\mathrm{T}$ has a fixed point $\mathrm{z} \in \mathrm{C}$.

Then $\mathrm{Tz}=\mathrm{z}$ so that $\mathrm{k}^{\mathrm{n}}\left(\mathrm{d}_{\mathrm{p}}\left(\mathrm{T}^{\mathrm{p}-1} \mathrm{z}, \mathrm{T}^{\mathrm{p}-2} \mathrm{z}, \ldots ., \mathrm{T} \mathrm{z}, \mathrm{z}\right)\right)=0$ giving that $\lim _{n \rightarrow \infty} \mathrm{k}^{\mathrm{n}}\left(\mathrm{d}_{\mathrm{p}}\left(\mathrm{T}^{\mathrm{p}-1} \mathrm{z}, \mathrm{T}^{\mathrm{p}-2} \mathrm{z}, \ldots, \mathrm{Tz}, \mathrm{z}\right)\right)=0$.

Let $\mathrm{T}_{1}$ denote the restriction of $\mathrm{T}^{-1}$ to $\mathrm{C}$, so that $\mathrm{T}_{1}: \mathrm{C} \rightarrow \mathrm{C}$ and (3.2) $d_{p}\left(T_{1} x_{1}, T_{1} x_{2}, \ldots, T_{1} x_{p}\right) \leq k\left(d_{p}\left(x_{1}, x_{2}, \ldots, x_{p}\right)\right)$ for all $\mathrm{x}_{1}, \mathrm{x}_{2}, \ldots, \mathrm{x}_{\mathrm{p}} \in \mathrm{C}$, since $\mathrm{TT}_{1}(\mathrm{x})=\mathrm{x}$ for all $\mathrm{x} \in \mathrm{C}$. Let $\mathrm{x}_{1} \in \mathrm{C}$ be arbitrary and $\mathrm{x}_{2}=\mathrm{T}_{1} \mathrm{x}_{1}, \mathrm{x}_{3}=\mathrm{T}_{1}^{2} \mathrm{x}_{1}, \ldots, \mathrm{x}_{\mathrm{p}}=\mathrm{T}_{1}^{\mathrm{p}-1} \mathrm{x}_{1}$.

Then (3.2) gives

$\mathrm{d}_{\mathrm{p}}\left(\mathrm{T}_{1} \mathrm{x}_{1}, \mathrm{~T}_{1}{ }^{2} \mathrm{x}_{1}, \ldots, \mathrm{T}_{1} \mathrm{p}_{1}\right) \leq \mathrm{k}\left(\mathrm{d}_{\mathrm{p}}\left(\mathrm{x}_{1}, \mathrm{~T}_{1} \mathrm{x}_{1}, \mathrm{~T}_{1}{ }^{2} \mathrm{x}_{1}, \ldots, \mathrm{T}_{1}^{\mathrm{p}-1} \mathrm{x}_{1}\right)\right)$

for all $\mathrm{x}_{1} \in \mathrm{C}$ which gives, in particular, that

$\mathrm{d}_{\mathrm{p}}\left(\mathrm{T}_{1} \mathrm{x}_{0}, \mathrm{~T}_{1}{ }^{2} \mathrm{x}_{0}, \ldots, \mathrm{T}_{1} \mathrm{p}_{0}\right) \leq \mathrm{k}\left(\mathrm{d}_{\mathrm{p}}\left(\mathrm{x}_{0}, \mathrm{~T}_{1} \mathrm{x}_{0}, \ldots, \mathrm{T}_{1}{ }^{\mathrm{p}-1} \mathrm{x}_{0}\right)\right)$

$$
\begin{aligned}
& \leq \mathrm{k}^{2}\left(\mathrm{~d}_{\mathrm{p}}\left(\mathrm{Tx}_{0}, \mathrm{TT}_{1} \mathrm{x}_{0}, \ldots, \mathrm{TT}_{1}^{\mathrm{p}-1} \mathrm{x}_{0}\right)\right) \\
& =\mathrm{k}^{2}\left(\mathrm{~d}_{\mathrm{p}}\left(\mathrm{Tx}_{0}, \mathrm{x}_{0}, \mathrm{~T}_{1} \mathrm{x}_{0}, \ldots, \mathrm{T}_{1}^{\mathrm{p}-2} \mathrm{x}_{0}\right)\right) .
\end{aligned}
$$

Now by induction, we get

$\mathrm{d}_{\mathrm{p}}\left(\mathrm{T}_{1}{ }^{\mathrm{n}-\mathrm{p}+1} \mathrm{x}_{0}, \mathrm{~T}_{1}^{\mathrm{n}-\mathrm{p}+2} \mathrm{x}_{0}, \ldots, \mathrm{T}_{1}{ }^{\mathrm{n}} \mathrm{x}_{0}\right) \leq \mathrm{k}^{\mathrm{n}}\left(\mathrm{d}_{\mathrm{p}}\left(\mathrm{T}^{\mathrm{p}-1} \mathrm{x}_{0}, \mathrm{~T}^{\mathrm{p}-2} \mathrm{x}_{0}, \ldots, \mathrm{Tx}_{0},{ }_{0}\right)\right)$. Hence $d_{p}\left(T_{1}{ }^{n-p+1} x_{0}, T_{1}{ }^{n-p+2} x_{0}, \ldots, T_{1}{ }^{n} x_{0}\right) \rightarrow 0$ as $n \rightarrow \infty$ which gives that $\left(T_{1}{ }^{n} x_{0}\right)$ is a $d_{p}-$ Cauchy sequence in $X$.

Since $X$ is $d_{p}-$ complete, the sequence $\left(T_{1}{ }^{n} x_{0}\right)$ converges to some point $\mathrm{z}$. That is, $\mathrm{T}_{1}{ }^{\mathrm{n}} \mathrm{x}_{0} \rightarrow \mathrm{z}$ as $\mathrm{n} \rightarrow \infty$.

Note that $\mathrm{z} \in \mathrm{C}$ since $\mathrm{C}$ is closed.

Now $\mathrm{T}_{1}\left(\mathrm{~T}_{1}{ }^{\mathrm{n}} \mathrm{x}_{0}\right) \rightarrow \mathrm{T}_{1} \mathrm{Z}$ as $\mathrm{n} \rightarrow \infty$ since $\mathrm{T}_{1}$ is w-continuous.

But $\mathrm{T}_{1}{ }^{\mathrm{n}+1} \mathrm{x}_{0} \rightarrow \mathrm{Z}$ as $\mathrm{n} \rightarrow \infty$ and since limits are unique in $\mathrm{X}$, we get that $T_{1} z=z$.

Now $T\left(T_{1} z\right)=T z$ gives $z=T z$ since $T\left(T_{1} z\right)=z$ and hence $T$ has a fixed point.

3.3 Remark: It may be noted that in view of Remark 1.3, the result proved by Linda Marie Saliga ([10], Theorem 1,pp.103,104) is a particular case of Theorem 3.1

3.4 Corollary: Suppose $\mathrm{T}: \mathrm{C} \rightarrow \mathrm{X}$ where $\mathrm{C}$ is a closed subset of a $\mathrm{d}_{\mathrm{p}}$-complete Hausdorff p-symmetrizable topological space with $\mathrm{C} \subset \mathrm{T}(\mathrm{C})$. Suppose $d_{\mathrm{p}}\left(\mathrm{x}_{1}, \mathrm{x}_{2}, \ldots, \mathrm{x}_{\mathrm{p}}\right) \leq$ $\left[\mathrm{d}_{\mathrm{p}}\left(\mathrm{Tx}_{1}, \mathrm{Tx}_{2}, \ldots, \mathrm{Tx}_{\mathrm{p}}\right)\right]^{\mathrm{s}}$ where $\mathrm{s}>1$ for all $\mathrm{x}_{1}, \mathrm{x}_{2}, \ldots \mathrm{x}_{\mathrm{p}} \in \mathrm{C}$. If there exists $\mathrm{x}_{0} \in \mathrm{C}$ such that $\mathrm{d}_{\mathrm{p}}\left(\mathrm{T}^{\mathrm{p}-1} \mathrm{x}_{0}, \mathrm{~T}^{\mathrm{p}-2} \mathrm{x}_{0}, \ldots, \mathrm{Tx}_{0}, \mathrm{x}_{0}\right)<1$, then $\mathrm{T}$ has a fixed point.

Proof Let $x, y$ be in $C$ with $x \neq y$.

Then $0<\mathrm{d}_{\mathrm{p}}(\mathrm{x}, \mathrm{y}, \mathrm{y}, \ldots, \mathrm{y}) \leq\left[\mathrm{d}_{\mathrm{p}}(\mathrm{Tx}, \mathrm{Ty}, \ldots, \mathrm{Ty})\right]^{\mathrm{s}}$ which gives

$\mathrm{Tx} \neq \mathrm{Ty}$.

Thus, $\mathrm{T}$ is one - one and hence $\mathrm{T}^{-1}: \mathrm{T}(\mathrm{C}) \rightarrow \mathrm{C}$ exists.

Now the inequality of the theorem gives

$d_{p}\left(T^{-1} x_{1}, T^{-1} x_{2}, \ldots, T^{-1} x_{p}\right) \leq\left[d_{p}\left(x_{1}, x_{2}, \ldots, x_{p}\right)\right]^{s}$ which implies that $\mathrm{T}^{-1}$ is continuous. Hence $\mathrm{T}$ must be an open map.

Let $\mathrm{x}_{0} \in \mathrm{C}$ be such that $\mathrm{d}_{\mathrm{p}}\left(\mathrm{T}^{\mathrm{p}-1} \mathrm{x}_{0}, \mathrm{~T}^{\mathrm{p}-2} \mathrm{x}_{0}, \ldots, \mathrm{Tx}_{0}, \mathrm{x}_{0}\right)<1$.

If $\mathrm{d}_{\mathrm{p}}\left(\mathrm{T}^{\mathrm{p}-1} \mathrm{x}_{0}, \mathrm{~T}^{\mathrm{p}-2} \mathrm{x}_{0}, \ldots, \mathrm{Tx}_{0}, \mathrm{x}_{0}\right)=0$, then $\mathrm{x}_{0}$ is a fixed point

of $\mathrm{T}$.

Suppose $0<d_{p}\left(T^{p-1} x_{0}, T^{p-2} x_{0}, \ldots, T x_{0}, x_{0}\right)<1$.

Let $\mathrm{k}(\mathrm{t})=\mathrm{t}^{\mathrm{s}}$ and $\mathrm{t}=\mathrm{d}_{\mathrm{p}}\left(\mathrm{T}^{\mathrm{p}-1} \mathrm{x}_{0}, \mathrm{~T}^{\mathrm{p}-2} \mathrm{x}_{0}, \ldots, \mathrm{Tx}_{0}, \mathrm{x}_{0}\right)$.

Note that $(\alpha \mathrm{t})^{\mathrm{s}}<\alpha \mathrm{t}^{\mathrm{s}}$ if $0<\alpha<1$. Since $\mathrm{t}^{\mathrm{s}}<\mathrm{t}$, there is an $\beta \in(0,1)$ such that $t^{s}=\beta \mathrm{t}$.

We claim that

(3.5) $\quad t^{\mathrm{ns}} \leq \beta^{\mathrm{n}} \mathrm{t}$ for all natural numbers $\mathrm{n}$.

For $\mathrm{n}=1,(3.5)$ holds. Now assume that (3.5) holds for $\mathrm{n}=\mathrm{k}$. That is, $\mathrm{t}^{\mathrm{ks}} \leq \beta^{\mathrm{k}} \mathrm{t}$.

Then $\mathrm{t}^{(\mathrm{k}+1) \mathrm{s}}=\mathrm{t}^{\mathrm{ks}} \mathrm{t}^{\mathrm{s}} \leq \beta^{\mathrm{k}} \mathrm{t} \beta \mathrm{t}$, since $\mathrm{t}^{\mathrm{s}}=\beta \mathrm{t}$

$$
\begin{aligned}
& =\beta^{\mathrm{k}+1} \mathrm{t}^{2} \\
& \leq \beta^{\mathrm{k}+1} \mathrm{t} \text {, since } 0<\mathrm{t}<1 .
\end{aligned}
$$

Hence, by induction, we get (3.5).

Therefore, $\mathrm{k}^{\mathrm{n}}\left(\mathrm{d}_{\mathrm{p}}\left(\mathrm{T}^{\mathrm{p}-1} \mathrm{x}_{0}, \mathrm{~T}^{\mathrm{p}-2} \mathrm{x}_{0}, \ldots, \mathrm{Tx}_{0}, \mathrm{x}_{0}\right)\right)$

$$
\begin{aligned}
& =\left[\mathrm{d}_{\mathrm{p}}\left(\mathrm{T}^{\mathrm{p}-1} \mathrm{x}_{0}, \mathrm{~T}^{\mathrm{p}-2} \mathrm{x}_{0}, \ldots, \mathrm{Tx}_{0}, \mathrm{x}_{0}\right)\right]^{\mathrm{ns}} \\
& =\mathrm{t}^{\mathrm{ns}} \leq \beta^{\mathrm{n}} \mathrm{t} \rightarrow 0 \text { as } \mathrm{n} \rightarrow \infty, \text { since } 0<\beta<1 \text { and }
\end{aligned}
$$

hence the theorem follows from Theorem 3.1.

It may be noted that the existence of a fixed point for $\mathrm{T}$ on a closed subset of a $\mathrm{d}_{\mathrm{p}}$-complete Hausdorff topological space $\left(\mathrm{X}, \mathrm{t}, \mathrm{d}_{\mathrm{p}}\right)$ is not ensured, if the inequality of the Theorem 3.1 is replaced by any one of the following :

$\mathrm{d}_{\mathrm{p}}\left(\mathrm{Tx}_{1}, \mathrm{Tx}_{2}, \ldots ., \mathrm{Tx}_{\mathrm{p}}\right) \geq \mathrm{k}\left(\mathrm{d}_{\mathrm{p}}\left(\mathrm{x}_{1}, \mathrm{x}_{2}, \ldots, \mathrm{x}_{\mathrm{p}}\right)\right)$ for all $\mathrm{x}_{1}, \mathrm{x}_{2}$, $\ldots \ldots, \mathrm{x}_{\mathrm{p}} \in \mathrm{C}$.

$d_{p}\left(x_{1}, x_{2}, \ldots, x_{p}\right) \geq k\left(d_{p}\left(\operatorname{Tx}_{1}, T_{2}, \ldots, T_{p}\right)\right)$ for all $x_{1}, x_{2}, \ldots .$, $\mathrm{x}_{\mathrm{p}} \in \mathrm{C}$.

$k\left(d_{p}\left(x_{1}, x_{2}, \ldots, x_{p}\right)\right) \geq d_{p}\left(\operatorname{Tx}_{1}, T_{2}, \ldots ., T x_{p}\right)$ for all $x_{1}, x_{2}, \ldots$, $\mathrm{x}_{\mathrm{p}} \in \mathrm{C}$.

L.M. Saliga has provided counter examples in the case $\mathrm{p}=2$ ([10], Examples 2,3,4, p.105,106).

3.6 Theorem: Let $\left(X, t, d_{p}\right)$ be a $d_{p}$ - complete Hausdorff topological space, $\mathrm{C}$ be a closed subset of $\mathrm{X}$ and $\mathrm{T}: \mathrm{C} \rightarrow \mathrm{X}$ with $\mathrm{C} \subset \mathrm{T}(\mathrm{C})$. Suppose there exists a function $\mathrm{k}:[0, \infty) \rightarrow[0$, $\infty)$ such that $\mathrm{k}\left(\mathrm{d}_{\mathrm{p}}\left(\mathrm{Tx}_{1}, \mathrm{Tx}_{2}, \ldots, \mathrm{Tx}_{\mathrm{p}}\right)\right) \geq \mathrm{d}_{\mathrm{p}}\left(\mathrm{x}_{1}, \mathrm{x}_{2}, \ldots, \mathrm{x}_{\mathrm{p}}\right)$ for all $\mathrm{x}_{1}, \mathrm{x}_{2}, \ldots \mathrm{x}_{\mathrm{p}} \in \mathrm{C}$, where $\mathrm{k}$ is a non-decreasing function with $\mathrm{k}(0)$ $=0$ and there exists an $\mathrm{x}_{0} \in \mathrm{C}$ such that $\mathrm{k}^{\mathrm{n}}\left(\mathrm{d}_{\mathrm{p}}\left(\mathrm{T}^{\mathrm{p}-1} \mathrm{x}_{0}, \mathrm{~T}^{\mathrm{p}-2} \mathrm{x}_{0}, \ldots\right.\right.$, $\left.\left.\mathrm{Tx}_{0}, \mathrm{x}_{0}\right)\right) \rightarrow 0$ as $\mathrm{n} \rightarrow \infty$. If $\mathrm{d}_{\mathrm{p}}\left(\mathrm{T}^{\mathrm{p}-1} \mathrm{x}, \mathrm{T}^{\mathrm{p}-2} \mathrm{x}, \ldots, \mathrm{Tx}, \mathrm{x}\right)$ is lower semi-continuous on $\mathrm{C}$, then $\mathrm{T}$ has a fixed point.

Proof: If $\mathrm{x}$ and $\mathrm{y}$ are in $\mathrm{C}$ with $\mathrm{x} \neq \mathrm{y}$. Then $0<\mathrm{d}_{\mathrm{p}}(\mathrm{x}, \mathrm{y}, \mathrm{y}, \ldots, \mathrm{y})$ $\leq \mathrm{k}\left(\mathrm{d}_{\mathrm{p}}(\mathrm{Tx}, \mathrm{Ty}, \ldots ., \mathrm{Ty})\right)$ gives that $\mathrm{Tx} \neq \mathrm{Ty}$. Hence $\mathrm{T}$ is one one and $\mathrm{T}^{-1}$ exists.Let $\mathrm{T}_{1}$ be the restriction of $\mathrm{T}^{-1}$ to $\mathrm{C}$. That is , $\mathrm{T}_{1}=\mathrm{T}^{-1} \mid \mathrm{C}$. Now $\mathrm{T}_{1}: \mathrm{C} \rightarrow \mathrm{C}$ and for $\mathrm{x} \in \mathrm{C}$, we have $\mathrm{d}_{\mathrm{p}}\left(\mathrm{x}, \mathrm{T}_{1} \mathrm{x}, \mathrm{T}_{1}{ }^{2} \mathrm{x}, \ldots, \mathrm{T}_{1}{ }^{\mathrm{p}-1} \mathrm{x}\right) \leq \mathrm{k}\left(\mathrm{d}_{\mathrm{p}}\left(\mathrm{T} \mathrm{x}, \mathrm{x}, \mathrm{T}_{1} \mathrm{x}, \ldots, \mathrm{T}_{1}{ }^{\mathrm{p}-2} \mathrm{x}\right)\right)$ $\leq \mathrm{k}^{2}\left(\mathrm{~d}_{\mathrm{p}}\left(\mathrm{T}^{2} \mathrm{x}, \mathrm{T} \mathrm{x}, \mathrm{x}, \mathrm{T}_{1} \mathrm{x}, \ldots, \mathrm{T}_{1}^{\mathrm{p}-3} \mathrm{x}\right)\right)$.

Hence, by induction, we get

(3.7) $d_{p}\left(T_{1}^{n-p+1} x, T_{1}^{n-p+2} x, \ldots, T_{1}^{n} x\right) \leq k^{n}\left(d_{p}\left(T^{p-1} x, T^{p-2} x, \ldots\right.\right.$, Tx)).

If there exists $\mathrm{x}_{0} \in \mathrm{C}$ such that $\mathrm{k}^{\mathrm{n}}\left(\mathrm{d}_{\mathrm{p}}\left(\mathrm{T}^{\mathrm{p}-1} \mathrm{x}_{0}, \mathrm{~T}^{\mathrm{p}-2} \mathrm{x}_{0}, \ldots, \mathrm{Tx}_{0}\right)\right)$ $\rightarrow 0$ as $\mathrm{n} \rightarrow \infty$, then $\mathrm{d}_{\mathrm{p}}\left(\mathrm{T}_{1}{ }^{\mathrm{n}-\mathrm{p}+1} \mathrm{x}_{0}, \mathrm{~T}_{1}{ }^{\mathrm{n}-\mathrm{p}+2} \mathrm{x}_{0}, \ldots, \mathrm{T}_{1}{ }^{\mathrm{n}} \mathrm{x}_{0}\right) \rightarrow 0$ as $\mathrm{n}$ $\rightarrow \infty$, by (3.7), which gives that $\left(T_{1}{ }^{n} x_{0}\right)$ is $d_{p}$-Cauchy. Since $X$ is $\mathrm{d}_{\mathrm{p}}$-complete, there exists $\mathrm{z} \in \mathrm{x}$ such that $\mathrm{T}_{1}{ }^{\mathrm{n}} \mathrm{x}_{0} \rightarrow \mathrm{z}$ as $\mathrm{n} \rightarrow \infty$. Note that $\mathrm{z} \in \mathrm{C}$ since $\mathrm{T}_{1}{ }^{\mathrm{n}} \mathrm{x}_{0} \in \mathrm{C}$ for all $\mathrm{n}$ and $\mathrm{C}$ is closed.

Now $\mathrm{d}_{\mathrm{p}}\left(\mathrm{T}^{\mathrm{p}-1} \mathrm{x}, \mathrm{T}^{\mathrm{p}-2} \mathrm{x}, \ldots, \mathrm{Tx}, \mathrm{x}\right)$ is lower semi-continuous on $\mathrm{C}$ gives $d_{p}\left(T^{p-1} z, T^{p-2} z, \ldots, T z, z\right) \leq \liminf d_{p}\left(T_{1}{ }^{n-p+1} x_{0}, T_{1}{ }^{n-p+2} x_{0}, \ldots\right.$, $\left.\mathrm{T}_{1}{ }^{\mathrm{n}} \mathrm{x}_{0}\right) \rightarrow 0$ as $\mathrm{n} \rightarrow \infty$ giving that $\mathrm{Tz}=\mathrm{z}$.

3.7 Remark: Note that the result proved by Linda Marie Saliga ([10], Theorem 2, pp.105) is a particular case of Theorem 3.6 .

3.8 Theorem: Let $\mathrm{C}$ be a compact subset of a Hausdorff topological space $(\mathrm{X}, \mathrm{t})$ and $\mathrm{d}_{\mathrm{p}}$ be a $\mathrm{p}$-non-negative on $\mathrm{X}$. Suppose $T: C \rightarrow X$ with $C \subset T(C), T$ and $G_{p}(x)$ are both continuous, and $G_{p}(T x)>G_{p}(x)$ for all $x \in T^{-1}(C)$ with $x \neq T x$. Then $\mathrm{T}$ has a fixed point in $\mathrm{C}$.

Proof: Since C is a compact subset of a Hausdorff topological space, we get that $\mathrm{C}$ is closed and since $\mathrm{T}: \mathrm{C} \rightarrow \mathrm{X}$ 
is continous, so $\mathrm{T}^{-1}(C)$ is closed. Hence $\mathrm{T}^{-1}(\mathrm{C})$ is compact since $\mathrm{T}^{-1}(\mathrm{C}) \subset \mathrm{C}$. Also, $\mathrm{G}_{\mathrm{p}}(\mathrm{x})$ is continuous so it attains its minimum on $\mathrm{T}^{-1}(\mathrm{C})$, say at $\mathrm{z}$. That is,

(3.9) $\mathrm{G}_{\mathrm{p}}(\mathrm{z}) \leq \mathrm{G}_{\mathrm{p}}(\mathrm{x})$ for all $\mathrm{x} \in \mathrm{T}^{-1}(\mathrm{C})$

Now $\mathrm{z} \in \mathrm{C} \subset \mathrm{T}(\mathrm{C})$ so there exists $\mathrm{y} \in \mathrm{T}^{-1}(\mathrm{C})$ such that $\mathrm{Ty}=\mathrm{z}$.

If $y \neq z$, then $G_{p}(z)=G_{p}(T y)>G_{p}(y)$ which is a contradiction to (3.9).

Thus $\mathrm{y}=\mathrm{z}=$ Ty is a fixed point of $\mathrm{T}$.

3.9 Remark: Note that the result proved by Linda Marie Saliga ([10], Theorem 3, pp.106) is a particular case of Theorem 3.8 .

3.10 Theorem : Let $C$ be a compact subset of a Hausdorff topological space $(X, t)$ and $d_{p}$ be a p-non-negative on $X$. Suppose $T: C \rightarrow X$ with $C \subset T(C), T$ and $G_{p}(x)$ are both continuous, $\mathrm{f}:[0, \infty) \rightarrow[0, \infty)$ is continuous and $\mathrm{f}(\mathrm{t})>0$ for $\mathrm{t} \neq$ 0 . If we know that $G_{p}(T x) \leq \lambda f\left(G_{p}(x)\right)$ where $0<\lambda<1$, for all $x \in T^{-1}(C)$ implies $T$ has a fixed point then $G_{p}(T x)<f\left(G_{p}(x)\right)$ for all $x \in T^{-1}(C)$ such that $f\left(G_{p}(x)\right) \neq 0$ gives a fixed point.

Proof: Since $\mathrm{C}$ is a compact subset of a Hausdorff space, it is closed and since $\mathrm{T}$ is continuous, $\mathrm{T}^{-1}(\mathrm{C})$ is closed and hence is compact since $\mathrm{T}^{-1}(\mathrm{C}) \subset \mathrm{C}$.

Suppose $G_{p}(x) \neq 0$ for all $x \in T^{-1}(C)$. Then $G_{p}(x)>0$ so that $\mathrm{f}\left(\mathrm{G}_{\mathrm{p}}(\mathrm{x})\right)>0$ for all $\mathrm{x} \in \mathrm{T}^{-1}(\mathrm{C})$.

Now define $\mathrm{p}(\mathrm{x})$ on $\mathrm{T}^{-1}(\mathrm{C})$ by

$\mathrm{p}(\mathrm{x})=\frac{G_{p}(T x)}{f\left(G_{p}(x)\right)}$. Then $\mathrm{p}$ is continuous since $\mathrm{T}, \mathrm{f}$ and $\mathrm{G}_{\mathrm{p}}(\mathrm{x})$ are continuous. Therefore $\mathrm{p}$ attains its maximum on $\mathrm{T}^{-1}(\mathrm{C})$, say at $\mathrm{z}$. That is, $\mathrm{p}(\mathrm{x}) \leq \mathrm{p}(\mathrm{z})$ for all $\mathrm{x} \in \mathrm{T}^{-1}(\mathrm{C})$.

Now $\mathrm{p}(\mathrm{x}) \leq \mathrm{p}(\mathrm{z})<1$ so $\mathrm{G}_{\mathrm{p}}(\mathrm{Tx}) \leq \mathrm{p}(\mathrm{z}) \mathrm{f}\left(\mathrm{G}_{\mathrm{p}}(\mathrm{x})\right)$ and $\mathrm{T}$ must have a fixed point.

3.11 Remark: Note that the result proved by Linda Marie Saliga ([10], Theorem 4, pp.106) is a particular case of Theorem 3.10 .

3.12 Theorem: Let $C$ be a compact subset of a Hausdorff toplogical space $(\mathrm{X}, \mathrm{t})$ and $\mathrm{d}_{\mathrm{p}}$ be a p-non-negative on $\mathrm{X}$. Suppose $\mathrm{T}: \mathrm{C} \rightarrow \mathrm{X}$ with $\mathrm{C} \subset \mathrm{T}(\mathrm{C}), \mathrm{T}$ and $\mathrm{G}_{\mathrm{p}}(\mathrm{x})$ are both continuous, $f:[0, \infty) \rightarrow[0, \infty)$ is continuous and $f(t)>0$ for $t \neq 0$. If we know that $G_{p}(T x) \geq \lambda f\left(G_{p}(x)\right)$ where $\lambda>1$, for all $\mathrm{x} \in \mathrm{T}^{-1}(\mathrm{C}) \quad$ implies $\mathrm{T}$ has a fixed point, then $G_{p}(T x)>f\left(G_{p}(x)\right)$ for all $x \in T^{-1}(C)$ such that $f\left(G_{p}(x)\right) \neq 0$ gives a fixed point.
Proof : Since $\mathrm{C}$ is a compact subset of a Hausdorff space, we get that $C$ is closed and since $T$ is continuous, $T^{-1}(C)$ is closed. Hence $\mathrm{T}^{-1}(\mathrm{C})$ is compact, since $\mathrm{T}^{-1}(\mathrm{C}) \subset \mathrm{C}$.

Suppose $G_{p}(x) \neq 0$ for all $x \in T^{-1}(C)$. Then $G_{p}(x)>0$ and $f\left(G_{p}(x)\right)>0$.

Now, define $\mathrm{p}(\mathrm{x})=\frac{G_{p}(T x)}{f\left(G_{p}(x)\right)}$.

Then $p$ is continuous, since $T, f$ and $G_{p}(x)$ are continuous and hence $\mathrm{p}$ attains its minimum on $\mathrm{T}^{-1}(\mathrm{C})$, say at $\mathrm{z}$. That is, $\mathrm{p}(\mathrm{z}) \leq$ $\mathrm{p}(\mathrm{x})$ for all $\mathrm{x} \in \mathrm{T}^{-1}(\mathrm{C})$.

Now $\mathrm{p}(\mathrm{x}) \geq \mathrm{p}(\mathrm{z})>1$ so $\mathrm{G}_{\mathrm{p}}(\mathrm{Tx}) \geq \mathrm{p}(\mathrm{z}) \mathrm{f}\left(\mathrm{G}_{\mathrm{p}}(\mathrm{x})\right)$ and $\mathrm{T}$ must have a fixed point.

3.13 Remark: Note that the result proved by Linda Marie Saliga ([10], Theorem 5, pp.106,107) is a particular case of Theorem 3.12 .

\section{REFERENCES}

[1] J. Achari, Results on fixed point theorems, Maths. Vesnik 2 (15) (30) (1978), 219-221.

[2] Ciric, B. Ljubomir, A certain class of maps and fixed point theorems, Publ. L'Inst. Math. (Beograd) 20 (1976), 73-77.

[3] B. Fisher, Fixed point and constant mappings on metric spaces, Rend. Accad. Lincei 61(1976), 329 - 332

[4] K.M. Ghosh, An extension of contractive mappings, JASSY 23(1977), 39-42.

[5] Troy. L. Hicks, Fixed point theorems for d-complete topological spaces I, Internet. J. Math \& Math. Sci. 15 (1992), 435-440.

[6] Troy. L. Hicks and B.E. Rhoades, Fixed point theorems for d-complete topological spaces II, Math. Japonica 37, No. 5(1992), 847-853.

[7] K. Iseki, An approach to fixed point theorems, Math. Seminar Notes, 3(1975), 193-202.

[8] S. Kasahara, On some generalizations of the Banach contraction theorem, Math. Seminar Notes, 3(1975), 161-169.

[9] S. Kasahara, Some fixed point and coincidence theorems in L-Spaces, Math. Seminar Notes, 3(1975), 181-187.

[10] Linda Marie Saliga, Fixed point theorems for nonselfmaps in d-complete topological spaces, Intenat. J. Math \& Maths. Sci. 19.1 (1996), 103-110. 